\title{
Physicochemical and rheological properties of rice-based gluten-free blends containing differently treated chickpea flours
}

\author{
Gokcen Kahraman $^{\mathrm{a}, \mathrm{b}, *}$, Sebnem Harsa ${ }^{\mathrm{a}}$, Mara Lucisano ${ }^{\mathrm{b}}$, Carola Cappa ${ }^{\mathrm{b}}$ \\ a Department of Food Engineering, Faculty of Engineering, Izmir Institute of Technology, 35430, Urla, Izmir, Turkey \\ b Department of Food, Environmental and Nutritional Sciences (DeFENS), Università degli Studi di Milano, Via G. Celoria 2, 20133 Milan, Italy
}

\section{A R T I C L E I N F O}

\section{Keywords:}

Gluten-free dough

Chickpea flour

Physicochemical properties

Dough viscoelasticity

\begin{abstract}
A B S T R A C T
This study focused on the evaluation of the physicochemical and rheological properties of chickpea flours and blends obtained by partially substituting rice flour $(25 \mathrm{~g} / 100 \mathrm{~g})$ with raw, roasted and dehulled chickpea flour. The characteristics of the resultant doughs were evaluated. In comparison with rice flour, blends containing chickpea flours exhibited high protein and fat content, a reduced retrogradation tendency (setback values of 404-415 vs. 479 Brabender Unit) and a higher foaming capacity and stability, which can be beneficial for their use in baked food formulations. However, roasting decreased foaming capacity and stability. Even if the rheofermentographic test evidenced a slight reduction in dough development, high $\mathrm{CO}_{2}$ retention capacity ( $\geq 98 \%$ ) and similar-to-lower leavening times were observed for doughs containing chickpea flours. Incorporating chickpea flours also caused an increase in the viscous and elastic moduli of rice-based doughs, resulting in a good structuring of the dough. The results of this study indicated that chickpea flours could be used as a healthy ingredient in gluten-free rice-based formulations.
\end{abstract}

\section{Introduction}

Gluten, a viscoelastic protein complex formed following the kneading process of wheat, rye or barley, may cause health problems such as celiac disease (CD), wheat allergy and non-celiac gluten sensitivity in a broad spectrum of populations. Among these disorders, $\mathrm{CD}$ is an autoimmune metabolic disease occurring in $1 \%$ of population worldwide (Reilly \& Green, 2012). In CD patients, the consumption of gluten-containing foods leads to damage of the small intestine with a consequent reduction in the absorption of nutrients. To date, the remedy for celiac and other gluten-related diseases is to exclude gluten from the diet. The gluten-free (GF) diet is a real challenge, especially for celiac patients, since very low amounts of gluten can trigger the symptoms.

In the last few decades, despite some improvements in the technological and nutritional quality of GF bread (Alvarez-Jubete, Auty, Arendt, \& Gallagher, 2010; Cappa, Barbosa-Cánovas, Lucisano, \& Mariotti et al., 2016; Cappa, Lucisano, \& Mariotti, 2016; Mariotti, Lucisano, Pagani, \& Ng, 2009; Mariotti et al., 2017), the protein enrichment of GF bread is still a research target for GF producing companies. Thus, the use of legumes is nowadays considered a promising strategy for GF bread production with enhanced nutritional properties.

Recently, pulses are of increasing interest due to their nutritional benefits (e.g., high levels of proteins, complex carbohydrates, micronutrients and vitamins), and thus their consumption is highly recommended. Apart from their consumption as a whole seed, pulses are used, after milling, in many food formulations (e.g., bakery products, pasta, baby foods, etc.).

Chickpeas, one of the most important pulses, are mostly produced in Turkey, India, Australia and Pakistan (FAO, 2016). Chickpeas can be consumed as grains, meal or snack. A special type of roasted chickpea snack, which is widely consumed in Turkey and countries nearby, is called leblebi. During leblebi-processing several steps such as tempering, moistening, resting and roasting are applied (Coşkuner \& Karababa, 2004) and the hulls of the chickpea seeds are almost completely removed. During processing, some chickpeas are split in half and separated from the whole seeds as by-products (Coşkuner \& Karababa, 2004). After milling, these broken parts could be introduced in different food formulations (e.g., bakery products, desserts, soups, etc.) as a cheap, sustainable and nutritious ingredient.

To date, few studies related to the evaluation of doughs containing chickpea flour alone or blended with other ingredients have been published (Aguilar, Albanell, Minarro, \& Capellas, 2015; Burešová, Kráčmar, Dvořáková, \& Středa, 2014; Ouazib, Garzon, Zaidi, \& Rosell, 2016). Furthermore, to the best of our knowledge, no comprehensive study has been published related to the evaluation of the properties of

\footnotetext{
* Corresponding author. Department of Food Engineering, Faculty of Engineering, Izmir Institute of Technology, 35430, Urla, Izmir, Turkey.

E-mail address: gokcenkomen@iyte.edu.tr (G. Kahraman).
} 
doughs containing chickpea flours in combination with rice flour.

The aim of this study was to evaluate the physicochemical properties of raw, dehulled and roasted chickpea flours and to study the effects of their addition to a rice-based bread dough.

\section{Materials and methods}

\subsection{Materials}

Rice flour (RF; Beneo-Remy NV, Leuven-Wijgmaal, Belgium) and dehulled chickpea flour (DCF; Homecraft Pulse 4101, Ingredion, Germany) were used "as is". Raw chickpea (Yayla, Ankara, Turkey) and roasted chickpea (Tuğba, Aydın, Turkey) seeds were obtained from a Turkish local market, and milled by a laboratory mill to obtain chickpea flour (CF) and roasted chickpea flour (RCF), having particle size $\leq 1 \mathrm{~mm}$. The other ingredients used in the dough were hydroxypropylmethylcellulose (HPMC, Benecel F4M, Ashland, USA), instant yeast (Pakmaya, Istanbul, Turkey), sugar, salt and sunflower oil.

\subsection{Bread dough preparation}

In order to evidence the effects of raw, roasted and dehulled chickpea flours on a rice-based dough, the physicochemical properties of RF, CF, RCF and DCF were first assessed. According to preliminary trails and the results of a previous study (Kahraman, 2016), three flour blends composed of RF (75.15 g/100 g flour) and CF (24.85 g/100 g flour), or RCF (24.85 g/100 g flour) or DCF (24.85 g/100 g flour) and their respective bread doughs $(\mathrm{RF}+\mathrm{CF}, \mathrm{RF}+\mathrm{RCF}$ and $\mathrm{RF}+\mathrm{DCF})$ were prepared and characterized (Table 1). Dough containing $100 \mathrm{~g} /$ $100 \mathrm{~g}$ rice flour was considered as reference.

The bread doughs were prepared by using the Brabender Farinograph (Brabender OHG, Germany). In addition to RF or flour blends, the bread dough formulation included HPMC $(1.72 \mathrm{~g} / 100 \mathrm{~g})$, sugar $(2 \mathrm{~g} / 100 \mathrm{~g})$, salt $(1.5 \mathrm{~g} / 100 \mathrm{~g})$, instant yeasts $(2.5 \mathrm{~g} / 100 \mathrm{~g})$, sunflower oil $(5.27 \mathrm{~g} / 100 \mathrm{~g})$ and water. All these percentages were based on RF or flour blend weight. The amount of water added to each formulation was determined in order to achieve a dough consistency of $125 \pm 5$ Brabender Unit (BU) (Kahraman, 2016). Dry components (RF or flour blends, HPMC, instant yeast, sugar and salt) were added to the farinograph bowl ( $300 \mathrm{~g}$ capacity) and mixed for $1 \mathrm{~min}$. Then, within $2 \mathrm{~min}$, part of the water, vegetable oil and the remaining water were added. The dough was eventually mixed for $8 \mathrm{~min}$ at $25^{\circ} \mathrm{C}$ and consistency was recorded.

\subsection{Flours and blends properties}

\subsubsection{Proximate composition and particle size distribution}

The moisture content of the flour samples was determined via oven drying at $105{ }^{\circ} \mathrm{C}$ until a constant weight was reached. The total nitrogen content of samples was determined according to the Official Standard

Table 1

Bread dough formulations.

\begin{tabular}{lcccc}
\hline Ingredients $(\mathrm{g} / 100 \mathrm{~g}$ of flour) & $\mathrm{RF}$ & $\mathrm{RF}+\mathrm{CF}$ & $\mathrm{RF}+\mathrm{RCF}$ & $\mathrm{RF}+\mathrm{DCF}$ \\
\hline $\mathrm{RF}$ & 100.00 & 75.15 & 75.15 & 75.15 \\
$\mathrm{CF}$ & - & 24.85 & - & - \\
$\mathrm{RCF}$ & - & - & 24.85 & - \\
$\mathrm{DCF}$ & - & - & - & 24.85 \\
HPMC & 1.72 & 1.72 & 1.72 & 1.72 \\
Sugar & 2.00 & 2.00 & 2.00 & 2.00 \\
Salt & 1.50 & 1.50 & 1.50 & 1.50 \\
Instant yeast & 2.50 & 2.50 & 2.50 & 2.50 \\
Sunflower oil & 5.27 & 5.27 & 5.27 & 5.27 \\
Water & 101.14 & 99.47 & 104.70 & 90.07
\end{tabular}

RF, rice flour; CF, chickpea flour; RCF, roasted chickpea flour; DCF, dehulled chickpea flour; HPMC, hydroxypropylmethylcellulose.
Method AOAC 920.87 (AOAC, 1999) by using a block digestion system (Kjeldatherm, C. Gerhardt GmbH \& Co. KG, Germany) and a distillation system (Vapodest 50s, C. Gerhardt GmbH \& Co. KG, Germany). Protein content was calculated using 5.95 and 6.25 as conversion factors for rice and chickpea flours, respectively. For fat content determination, flour samples $(4 \mathrm{~g}$ ) were extracted with n-hexane (Sigma-Aldrich, Germany) by using an automatic extraction system (Soxtherm, Gerhardt, Germany). Ash content was analyzed according to AACC (1999) by using a muffle furnace (Protherm, Turkey). The evaluations were done in triplicate and the results were expressed as percentages on dry basis (db).

For the flour particle size distributions, $50 \mathrm{~g}$ of sample was placed in an analytical sieve shaker (Octagon Digital, Endecotts Ltd., England) equipped with 5 sieves with 90,125, 250, 500 and $1000 \mu \mathrm{m}$ openings. Plastic balls having diameters of $3 \mathrm{~cm}$ were placed on sieves in order to facilitate sample distribution. Each fraction was collected after sieving at amplitude 8 for $10 \mathrm{~min}$. Results are the average of three determinations and are given as percentages of each fraction per $100 \mathrm{~g}$ flour.

\subsubsection{Scanning electron microscopy (SEM) analysis}

In order to investigate the effects of the different treatment on the flour microstructure, the images of flours were captured by scanning electron microscope (XL 30S FEG, Philips) under a voltage of $2.0 \mathrm{kV}$. Double-sided carbon tape having flour samples on one side was attached to an aluminum stub and coated with gold under vacuum $(9 \mathrm{~Pa})$.

\subsubsection{Water binding capacities and foaming properties}

To assess water binding capacity (WBC) of RF and flour blends, each sample $(2 \mathrm{~g})$ was mixed with deionized water $(24 \mathrm{~mL})$, shaken for $60 \mathrm{~min}$ (KS 130 Basic, IKA, Germany) and centrifuged at $3460 \times \mathrm{g}$ at $25^{\circ} \mathrm{C}$ for $10 \mathrm{~min}$ (Universal 320R, Hettich, Germany). The supernatant was carefully discarded and the weights of the tubes were recorded. The results (average of three measurements) were given as amount of water held by the dry sample ( $\mathrm{g}$ water/g db).

Foam capacity (FC) and stability (FS) of RF and flour blends were determined according to Shevkani, Singh, Kaur, and Rana (2015) with some modifications. The sample $(2 \mathrm{~g})$ was mixed with deionized water $(50 \mathrm{~mL})$ and homogenized for $2 \mathrm{~min}$ (Ultra-Turrax T 25, 18G Dispenser, IKA, Germany). FC (\%) was calculated as the volume ratio of foam and initial volume, and FS (\%) was given as the ratio of foam volume measured after $60 \mathrm{~min}$ with respect to initial foam volume. Four replications were performed.

\subsubsection{Pasting properties}

$\mathrm{RF}$ and flour blends were analyzed for their pasting properties by using Brabender ${ }^{\bullet}$ Micro-Visco-Amylograph (MVA) (Brabender OHG, Duisburg, Germany) according to Cappa, Lucisano, and Mariotti (2013). Sample slurry was prepared by dispersing sample (12 g) in distilled water $(100 \mathrm{~mL})$, scaling sample and water weight on $14 \mathrm{~g}$ / $100 \mathrm{~g}$ sample moisture basis. The measured indices were: gelatinization temperature $\left(\mathrm{GT},{ }^{\circ} \mathrm{C}\right.$; temperature at which an initial increase in viscosity occurs); peak viscosity (PV, BU; maximum paste viscosity achieved during heating), breakdown (BD, BU; viscosity decrease index while kept at $95^{\circ} \mathrm{C}$ ); final viscosity (FV, BU; paste viscosity at the end of the cooling), and setback (SB, BU; index of the viscosity increase during cooling). The analysis was performed in triplicate.

\subsection{Bread dough evaluation}

\subsubsection{Leavening properties}

The leavening behavior of the dough samples was evaluated with a Chopin Rheofermentometer F3 (Chopin, Villeneuve-La-Garenne, Cedex, France) according to a method developed for gluten-free dough samples (Cappa et al., 2013). The leavening was carried out at $30^{\circ} \mathrm{C}$ for $60 \mathrm{~min}$. Maximum and final heights ( $\mathrm{Hm}$ and $\mathrm{Hf}, \mathrm{mm}$ ) of the doughs, time necessary to reach maximum height (T1, min), time for dough porosity to 
appear ( $\mathrm{Tx}, \mathrm{min})$, total $\mathrm{CO}_{2}$ production $\left(\mathrm{CO}_{2 \text {-тот, }} \mathrm{ml}\right), \mathrm{CO}_{2}$ retention $\left(\mathrm{CO}_{2 \text {-RET }}, \mathrm{ml}\right)$, released $\mathrm{CO}_{2}\left(\mathrm{CO}_{2 \text {-REL }}, \mathrm{ml}\right)$ and coefficient of retention (Rc, \%) were measured. For each formulation, three replications were performed.

As a parallel test to the rheofermentometric test, the leavening properties of dough samples were measured by using image analysis with the method developed by Cappa et al. (2013). The dough area increase (\%) during leavening time was calculated. Six petri dishes per each sampling time (every $10 \mathrm{~min}$ ) were analyzed.

\subsubsection{Rheological properties}

The fundamental rheological behavior of the dough was studied by dynamic oscillatory measurements performed on a Physica MCR300 Rheometer (Anton Paar, Graz, Austria). The measurements were carried out with a corrugated parallel plate system (PP25/P2, diameter: $25 \mathrm{~mm}$ ) having a gap of $2 \mathrm{~mm}$. The dough samples were prepared as reported in $\S 2.2$ without adding instant yeast to avoid perturbation of the system during the analysis. Furthermore, dough samples rested for $60 \mathrm{~min}$ at $25^{\circ} \mathrm{C}$ before each measurement, then the dough was loaded between the plates and the excess amount was trimmed off. In order to avoid moisture loss during analysis, a humidity cover (H-PTD 150) having a water trap and wet pads was used, and mineral oil was carefully applied to dough borders. After $5 \mathrm{~min}$ of resting to relax stresses, the measurements were carried out and the data were recorded by using Universal Software US200 (version 2.5) (Anton Paar, Ostfildern, Germany). The strain sweep test was performed at a constant frequency of $1 \mathrm{~Hz}$ and in the range of $0.01-100 \%$ strain to determine the maximum strain amplitude at which the viscoelastic properties were independent of strain (linear viscoelastic region). According to strain sweep tests, $0.04 \%$ strain was selected as the strain amplitude for all the doughs analyzed. Frequency sweep tests were carried out in the range of 10 to $0.1 \mathrm{~Hz}$ at a constant strain of $0.04 \%$. For both tests, storage modulus $\left(\mathrm{G}^{\prime}, \mathrm{Pa}\right)$, loss modulus $\left(\mathrm{G}^{\prime \prime}, \mathrm{Pa}\right)$ and damping factor $(\tan \delta$, the ratio of $G^{\prime \prime}$ to $G^{\prime}$ ) were calculated. For each formulation, the analysis was performed in duplicate on two doughs separately prepared, thus the results are the average of four measurements.

\subsection{Statistical evaluation}

Statistical evaluation of the data was performed by using MINITAB 16 (Minitab Inc., U.S.). The results were given as "mean \pm SD". The significance of the data was tested by analysis of variance (ANOVA) at $\mathrm{p}<0.05$ and, in the significant models, means were compared by Tukey's test at $95 \%$ confidence interval.

\section{Results and discussion}

\subsection{Flour and blend physicochemical properties}

\subsubsection{Proximate composition and particle size distribution}

The proximate composition of rice and chickpea flours is listed in Table 2. The chickpea flours resulted richer in protein, fat and ash in comparison to RF. In particular, the protein content of chickpea flours was approximately three times the RF amount thus making the addition of chickpea flours into GF formulations an interesting strategy to increase the protein content of GF products. The fat content was comparable to the values reported by Alajaji and El-Adawy (2006) and Kaur, Singh, and Sodhi (2005). It must be emphasized that chickpea contains a higher level of linoleic and oleic acid and polyunsaturated fatty acids (PUFA) (Jukanti, Gaur, Gowda, \& Chibbar, 2012) in comparison with other pulses.

Comparing the different chickpea treatments, since heat was applied during the roasting process and hulls were almost completely removed, RCF showed almost three times lower moisture content than CF. Also the dehulling process resulted in a reduction of moisture, but to a lower extent than roasting. Even if some modifications in

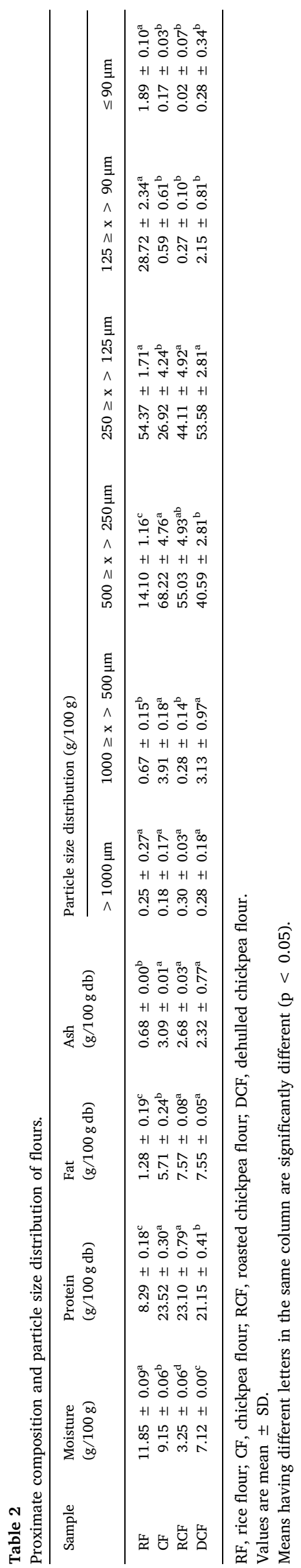


carbohydrates and proteins were reported by Coşkuner and Karababa (2004), roasting caused no statistical change in the amount of protein. No significant changes in protein content, as well as in ash and fiber, during roasting processing were previously observed by Sağlam (2006). The removal of hulls, rich in minerals, caused a $25 \%$ reduction in ash as evidenced by Ghavidel and Prakash (2007).

When unconventional flours are incorporated into baked products, the particle size distribution of the new ingredients has to be considered as it may affect some properties such as the hydration rate and the pasting behavior. The particle size distribution of the flours was quite different and covered a wide range (Table 2). In general, the chickpea flours had a larger particle size than RF. In fact, according to their particle size and starting from the flour characterized by the larger particles, flours could be ranked as CF, RCF, DCF and RF (having respectively $72.31,55.60,43.99,15.02 \mathrm{~g} / 100 \mathrm{~g}$ of particles bigger than $250 \mu \mathrm{m})$. The particle size distribution may be affected by the structure of the seed and the milling process (Schober, 2009). Comparing the two samples milled on laboratory scale (CF and RCF), the effect of the roasting process appears clear: flour resulting from roasted sample was characterized by smaller particles (Table 2); this brittle behavior during milling could be due to the expansion of air that takes place during seed roasting.

\subsubsection{Microstructure}

The scanning electron micrographs of RF and chickpea flours can be seen in Fig. 1. According to micrograph, the granule sizes of starches ranged from 5 to $12 \mu \mathrm{m}$ (average size: $10 \mu \mathrm{m}$ ) for RF, from 13 to $30 \mu \mathrm{m}$ (average size: $22 \mu \mathrm{m}$ ) for CF, from 14 to $26 \mu \mathrm{m}$ (average size: $19 \mu \mathrm{m}$ ) for RCF, and from 11 to $27 \mu \mathrm{m}$ (average size: $19 \mu \mathrm{m}$ ) for DCF. Previously, average granule sizes of $19-35 \mu \mathrm{m}$ and $19-26 \mu \mathrm{m}$ for raw and roasted pulse flours were reported, respectively (Ma et al., 2011). As seen in Fig. 1, rice starch granules had a polyhedral shape and they were smaller and in aggregated form in comparison with chickpea granules. Chickpea flours (CF, RCF, DCF), on the other hand, exhibited starch granules of spherical shapes covered with protein fragments. For all samples, intact starch granules were detected, although partial gelatinization of starch occurred in RCF, suggesting the roasting and dehulling treatments do not affect starch granula organization so much. Similarly, Köksel, Sivri, Scanlon, and Bushuk (1998) stated that starch was not completely gelatinized during roasting due to limited kernel hydration.

\subsubsection{Water binding capacity and foaming properties}

The addition of CF, RCF, and DCF to RF caused a slight decrease in WBC (Fig. 2), which was significant $(p<0.05)$ only for DCF. In the literature it is reported that flour having small particle size has high water binding capacity (Kim \& Shin, 2014) and this behavior has been related to the greater specific surface area of the flour. However, DCF, the chickpea flour with the smallest particle size, had the lowest water binding capacity. This contradictory finding can be attributed to husk removal during the dehulling process and thus to the different sample composition (Table 2). Since husks are sources of non-starch polysaccharides and proteins, their removal might have modified flour water binding capacity and dough rheology (Witczak, Ziobro, Juszczak, \& Korus, 2015).

As in GF dough production, the absence of gluten penalizes dough structuring, hydrocolloids and proteins are often used for their property of binding water, and foaming capacity. The foaming capacity and stability of RF and flour blends are reported in Fig. 2. Increased foam formation was observed in chickpea-containing blends $(\mathrm{p}<0.05)$. However, RF + RCF showed significantly lower FC compared to CF and DCF containing blends. The reduced foaming capacity of roasted chickpeas in comparison to the raw chickpea flour was previously reported by Ma et al. (2011) and related to the lower solubility of proteins as a result of the heat treatment.

As regards foam stability, rice flour exhibited no detectable foam after $60 \mathrm{~min}$ at room temperature; whereas the replacement of $24.85 \mathrm{~g} /$ $100 \mathrm{~g}$ flour of RF with chickpea flours highly improved foam stability. These findings are promising as the chickpea flours here are suggested as ingredients for GF bread dough in which a high capacity to retain leavening gas during baking is desirable. Of all the chickpea-containing samples, RF + RCF exhibited the lowest foam stability. Conversely, Ma
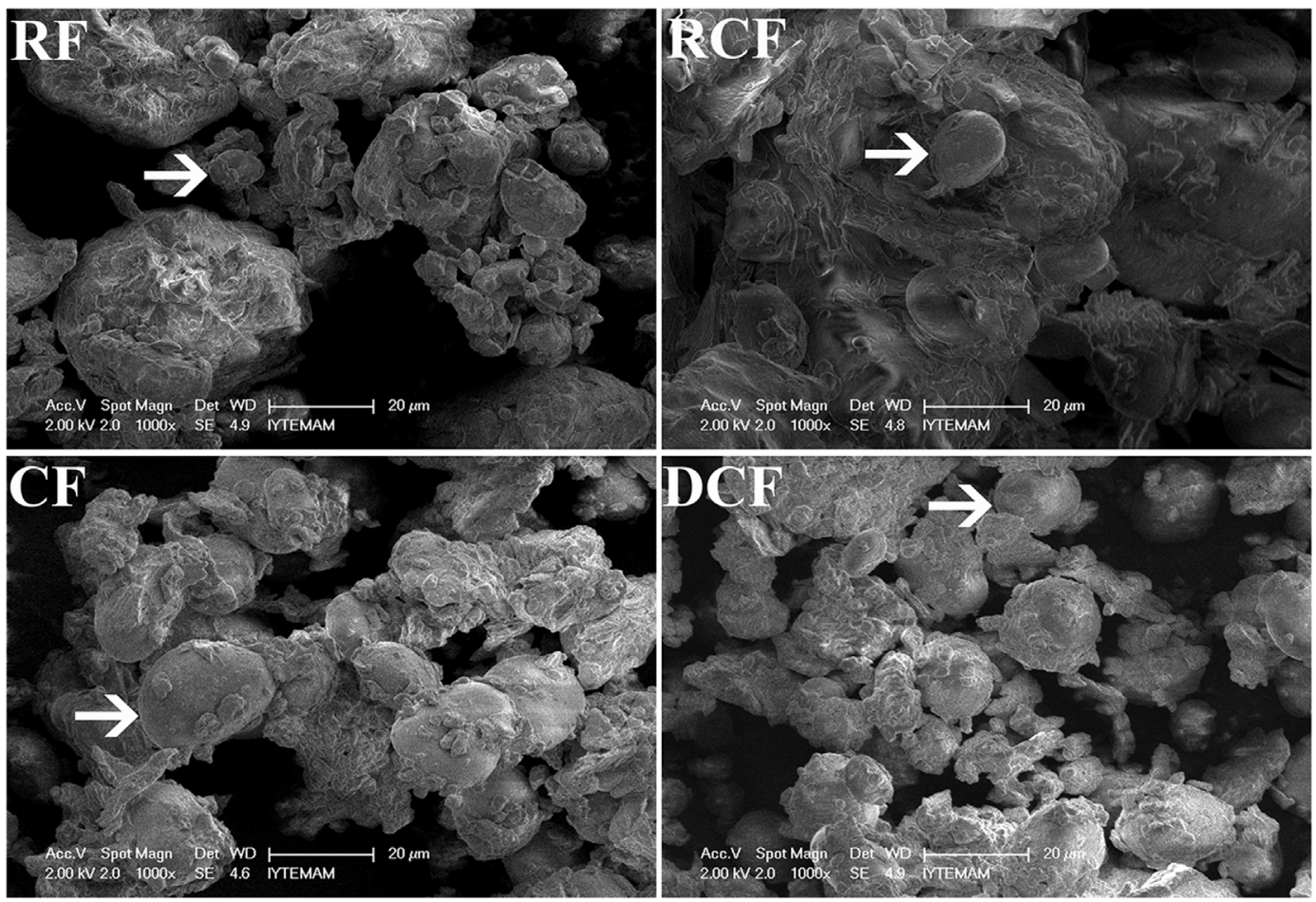

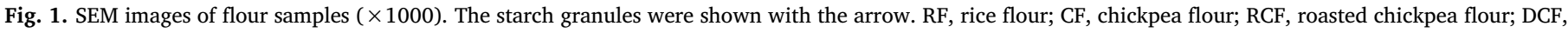
dehulled chickpea flour. 

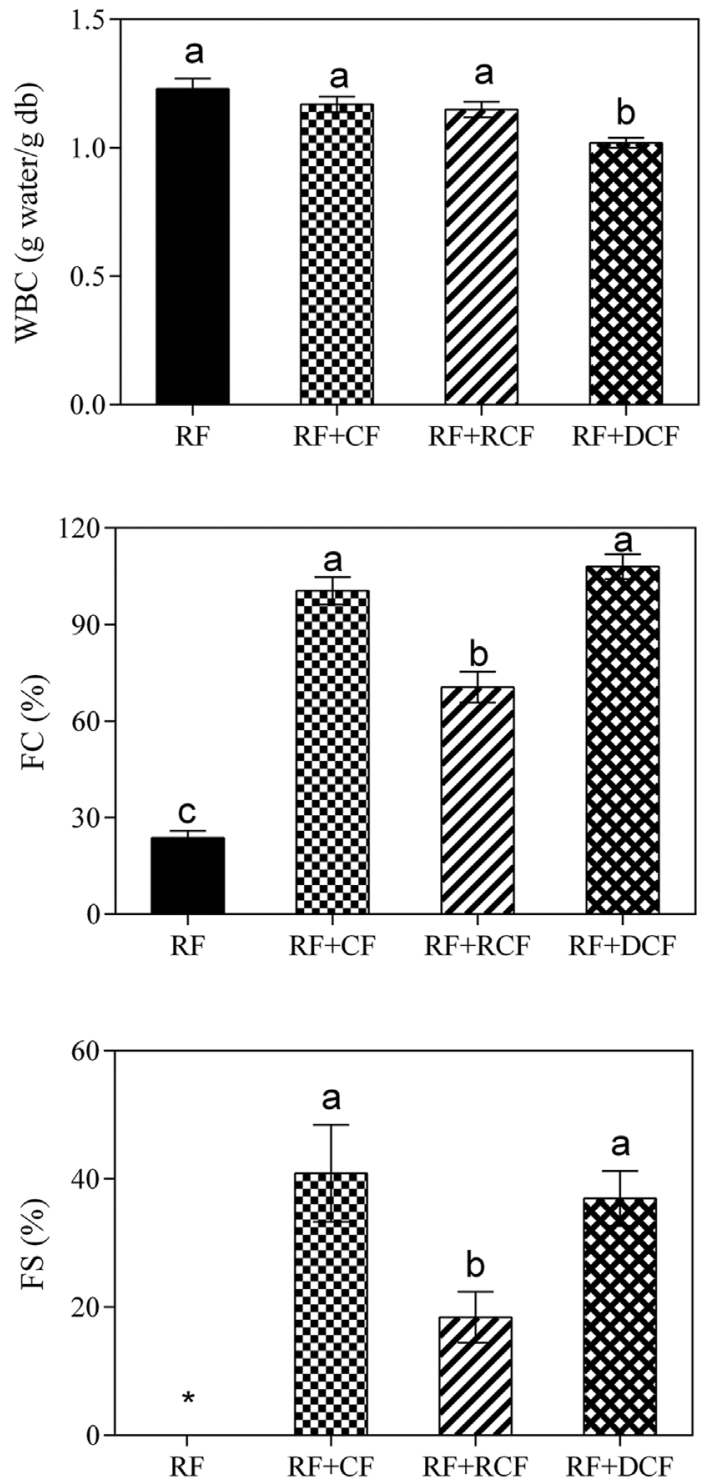

Fig. 2. Water binding capacities (WBC), foaming capacity (FC) and foam stability (FS) of RF and flour blends. RF, rice flour; CF, chickpea flour; RCF, roasted chickpea flour; DCF, dehulled chickpea flour; * no detectable foam after $60 \mathrm{~min}$. Means having different letters are significantly different $(\mathrm{p}<0.05)$.

et al. (2011) did not find any difference between raw and roasted chickpea flours in terms of foam stability. This can be related to the differences in the roasting processes; in this study, heating and roasting processes were directly applied to whole chickpea seeds in sequence instead of one stage of roasting applied to flour by Ma et al. (2011).

\subsubsection{Pasting properties}

The pasting curves of RF and flour blends (data not shown) were characterized by an increase in viscosity upon heating, since starch granules started to uptake water and swelled, and then a paste was obtained. During the holding period at $95{ }^{\circ} \mathrm{C}$ the starch gel viscosity decreased due to the shearing force applied. With cooling, the reordering of starch molecules caused a new increase in viscosity. This trend was displayed by all samples but to different extents. The pasting curve indices are reported in Table 3. It is well known that the pasting properties are mainly affected by the quantity and quality of starch and by the flour particle size (Kim \& Shin, 2014). All flour blends, in comparison to RF, exhibited lower peak viscosity, final viscosity, breakdown and setback values. This behavior is mainly due to the composition of chickpea flours and it indicates that the addition of chickpea flour, besides producing a lower strength gel, may slow down paste retrogradation (i.e., low SB) and thus limit the staling of baked food.

Of the three chickpea-containing blends, the maximum viscosity reached during the heating period (PV) and the final viscosity were lower for RF + RCF, which indicates that roasting had a slight effect on starch gelatinization in accordance with the scanning images. It is to note that roasting was performed with the addition of a small amount of water and thus the heat treatment did not exhibit a relevant effect on pasting behavior.

\subsection{Bread dough properties}

In order to reach the desired (125 $\pm 5 \mathrm{BU}$; Kahraman, 2016) dough consistency, and in accordance with the WBC data, RF + DCF required less water in comparison to the other dough (90.07 vs. 101.14, 99.47, $104.70 \mathrm{~g} / 100 \mathrm{~g}$ flour, for RF + DCF, RF, RF + CF, RF + RCF, respectively). These differences are related to flour composition and to their ability to adsorb water, as previously discussed.

\subsubsection{Leavening properties}

The best leaving performance in terms of maximum and final dough height was evidenced by RF dough (Table 4). This is in accordance with the general findings that flour ingredients containing fiber - such as chickpea flours - resulted in weak dough structure. However, the $\mathrm{CO}_{2}$ retention capacity of RF + RCF (98.6\%) was higher than RF + CF (97.7\%) and RF + DCF (98.1\%), and slightly lower than RF (99.4\%). This suggests a slight weakening of the dough containing chickpea flours, which were in any case able to retain the majority of the $\mathrm{CO}_{2}$ produced by the yeast. The advantages of using chickpea flours can be seen in terms of total $\mathrm{CO}_{2}$ produced. In fact, for the three formulations containing chickpea flours, the production of $\mathrm{CO}_{2}\left(\mathrm{CO}_{2 \text {-тот }}\right)$ was $5-11 \%$ higher than in RF. This can be due to the higher amount of fermentable sugars used by yeast (10.85 g sugar/100 g chickpea flour; $0.12 \mathrm{~g}$ sugar/ $100 \mathrm{~g}$ rice flour) (USDA, 2016). Furthermore, RF + CF and RF + DCF were also characterized by an earlier appearance of $\mathrm{Tx}$, thus a shorter leavening process is recommended for their baking.

Dough leavening behavior was also monitored by means of image analysis. This technique has been proposed as an alternative tool to the Rheofermentometer by evaluating dough development as an increase in dough area (Cappa et al., 2013). All doughs were able to increase their area (up to a maximum value of $114 \%$ after $60 \mathrm{~min}$ of leavening) and for each formulation, the dough area increase during leavening was

Table 3

Pasting properties of RF and flour blends.

\begin{tabular}{|c|c|c|c|c|c|}
\hline Sample & $\mathrm{GT}\left({ }^{\circ} \mathrm{C}\right)$ & PV (BU) & $\mathrm{BD}(\mathrm{BU})$ & $\mathrm{SB}(\mathrm{BU})$ & $\mathrm{FV}(\mathrm{BU})$ \\
\hline $\mathrm{RF}$ & $77.15 \pm 0.07^{\mathrm{bc}}$ & $716.50 \pm 7.78^{\mathrm{a}}$ & $326.50 \pm 12.02^{\mathrm{a}}$ & $478.50 \pm 9.19^{\mathrm{a}}$ & $868.50 \pm 13.44^{\mathrm{a}}$ \\
\hline $\mathrm{RF}+\mathrm{CF}$ & $76.80 \pm 0.14^{\mathrm{ab}}$ & $503.50 \pm 2.12^{\mathrm{b}}$ & $196.50 \pm 6.36^{\mathrm{b}}$ & $410.00 \pm 4.24^{\mathrm{b}}$ & $717.00 \pm 0.01^{b}$ \\
\hline $\mathrm{RF}+\mathrm{RCF}$ & $77.60 \pm 0.01^{\mathrm{a}}$ & $435.50 \pm 12.02^{c}$ & $161.50 \pm 9.19^{c}$ & $404.00 \pm 7.07^{b}$ & $678.00 \pm 9.90^{c}$ \\
\hline $\mathrm{RF}+\mathrm{DCF}$ & $77.40 \pm 0.14^{\mathrm{c}}$ & $498.00 \pm 5.66^{\mathrm{b}}$ & $164.00 \pm 4.24^{\mathrm{bc}}$ & $415.00 \pm 5.66^{b}$ & $749.00 \pm 4.24^{b}$ \\
\hline
\end{tabular}

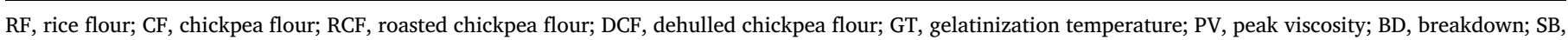
setback; FV, final viscosity. Values are mean \pm SD. Means having different letters in the same column are significantly different (p < 0.05 ). 
Table 4

Dough leavening properties.

\begin{tabular}{|c|c|c|c|c|c|c|c|}
\hline Sample & $\mathrm{Hm}(\mathrm{mm})$ & $\mathrm{Hf}(\mathrm{mm})$ & $\mathrm{Tx}(\min )$ & $\mathrm{CO}_{2 \text {-тот }}(\mathrm{mL})$ & $\mathrm{CO}_{2-\mathrm{REL}}(\mathrm{mL})$ & $\mathrm{CO}_{2 \text {-RET }}(\mathrm{mL})$ & Rc (\%) \\
\hline $\mathrm{RF}$ & $49.8 \pm 0.8^{\mathrm{b}}$ & $49.8 \pm 0.8^{c}$ & $54.5 \pm 3.5^{\mathrm{b}}$ & $803 \pm 28.3^{\mathrm{a}}$ & $5 \pm 0.01^{\mathrm{a}}$ & $799 \pm 27.6^{\mathrm{a}}$ & $99.35 \pm 0.1^{c}$ \\
\hline $\mathrm{RF}+\mathrm{CF}$ & $41.0 \pm 0.4^{\mathrm{a}}$ & $36.5 \pm 0.6^{\mathrm{a}}$ & $42.8 \pm 1.1^{\mathrm{a}}$ & $892 \pm 23.3^{\mathrm{a}}$ & $20 \pm 2.80^{c}$ & $872 \pm 20.5^{\mathrm{a}}$ & $97.70 \pm 0.3^{\mathrm{a}}$ \\
\hline $\mathrm{RF}+\mathrm{RCF}$ & $40.6 \pm 1.6^{\mathrm{a}}$ & $36.5 \pm 1.0^{\mathrm{a}}$ & $48.0 \pm 2.1^{\mathrm{ab}}$ & $840 \pm 26.9^{\mathrm{a}}$ & $12 \pm 4.90^{\mathrm{ab}}$ & $828 \pm 22.6^{a}$ & $98.60 \pm 0.5^{b c}$ \\
\hline $\mathrm{RF}+\mathrm{DCF}$ & $41.4 \pm 2.5^{\mathrm{a}}$ & $40.3 \pm 1.0^{\mathrm{b}}$ & $43.5 \pm 2.1^{\mathrm{a}}$ & $871 \pm 11.3^{\mathrm{a}}$ & $17 \pm 0.01^{\mathrm{bc}}$ & $854 \pm 12.0^{\mathrm{a}}$ & $98.10 \pm 0.1^{\mathrm{ab}}$ \\
\hline
\end{tabular}

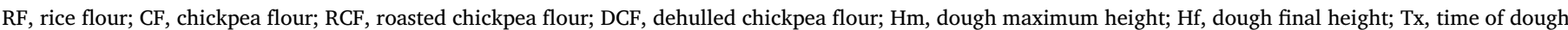

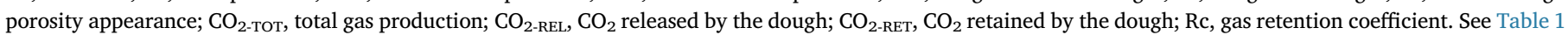
for sample formulations.
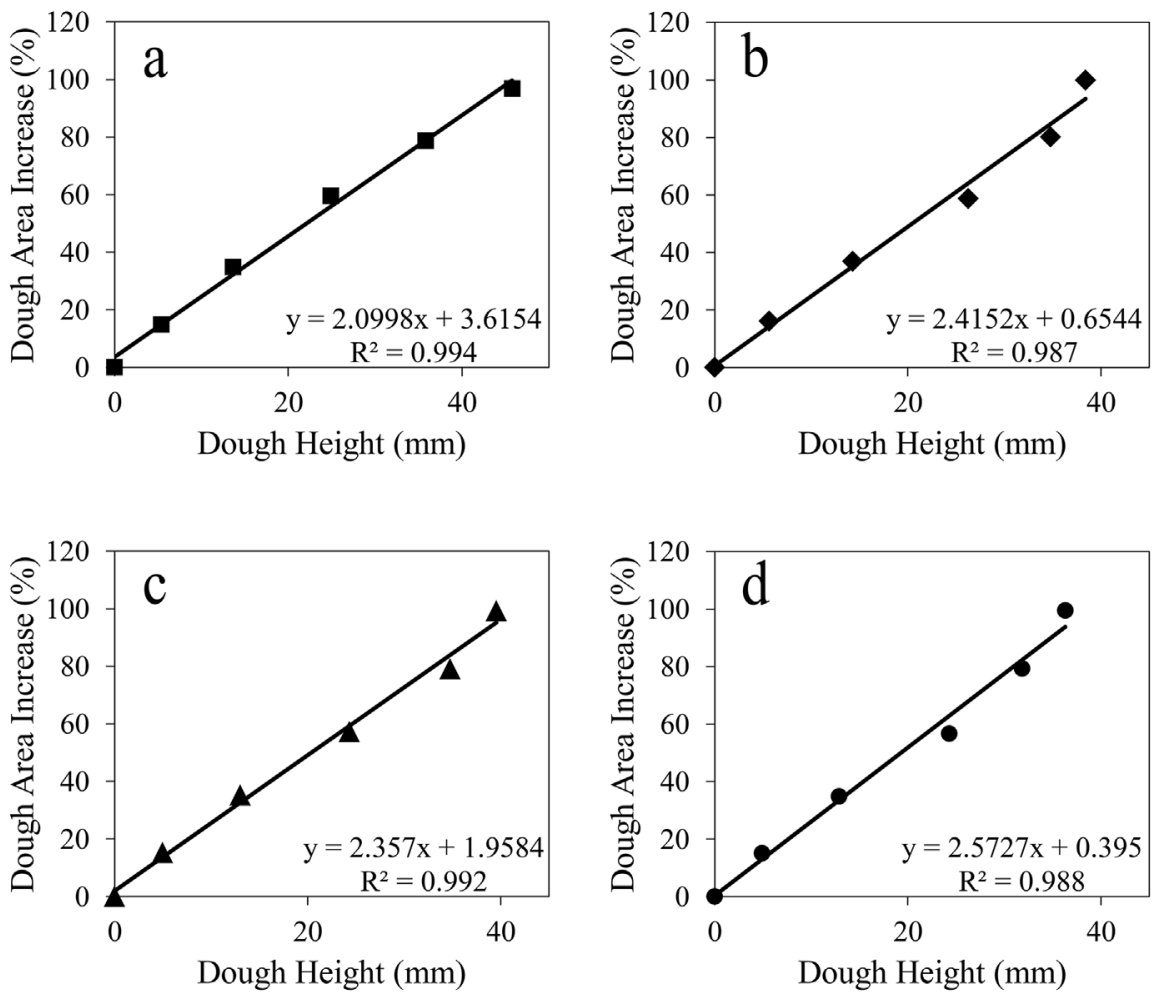

Fig. 3. Dough area increase vs. dough height obtained via image analysis and Rheofermentographic test, respectively. a) RF, rice flour ( $\square$ ); b) $R F+C F$, rice and chickpea flour $(\diamond), \mathrm{c}) \mathrm{RF}+\mathrm{RCF}$, rice and roasted chickpea flour ( $\mathbf{\Delta}$ ) and d) RF + DCF, rice and dehulled chickpea flour (O). See Table 1 for sample formulations.

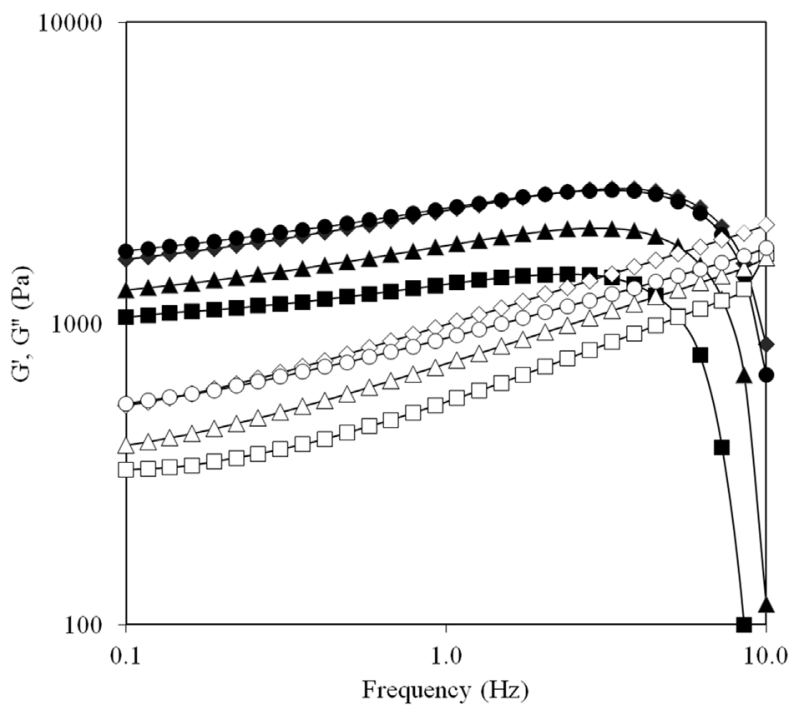

Fig. 4. Dough viscoelastic properties: frequency sweep tests. RF, rice flour; CF, chickpea flour; RCF, roasted chickpea flour; DCF, dehulled chickpea flour. Storage modulus ( $\mathrm{G}^{\prime}$, dark), loss modulus ( $\mathrm{G}^{\prime \prime}$, white), RF $(\square), \mathrm{RF}+\mathrm{CF}(\diamond)$, $\mathrm{RF}+\mathrm{RCF}(\mathbf{\Delta})$ and $\mathrm{RF}+\operatorname{DCF}(\mathbf{\bullet})$. highly correlated to the values of dough height obtained from the Rheofermentometer test $\left(R^{2} \geq 0.98\right.$; Fig. 3), suggesting that both tests can be used to study dough development.

\subsubsection{Rheological properties}

The deformation applied during the dynamic test is often very different from those experienced by the dough during real processing (i.e., mixing, leavening, baking). However, these measurements provide unique information about the viscoelastic characteristic of the dough by preserving the dough structure during the test. Accordingly, the viscoelastic properties measured can be used to compare different dough formulations. The strain sweep test was firstly performed to delineate the region of linear viscosity in order to define when dough characteristics do not depend on the magnitude of the deforming strain. For all the samples, $G^{\prime}$ and $G^{\prime \prime}$ remained almost constant at least up to $0.04 \%$ strain (data not shown). Beyond this limit, the storage and loss moduli decreased, indicating a progressive destruction of the dough structure. Similar limits of linear viscoelasticity were found in the literature for GF doughs (Mariotti et al., 2009).

According to the region of linear viscosity, the frequency sweep test was performed at a constant strain of $0.04 \%$, in the range of 10 to $0.1 \mathrm{~Hz}$. Frequency sweep curves are reported in Fig. 4. Although all the dough samples had the same final farinographic consistency (125 \pm 5 $\mathrm{BU})$, they differed in terms of fundamental rheological properties. According to Mariotti et al. (2009), no relationships were found between 
the different water levels in the GF doughs and the values of their respective dynamic moduli. For all dough formulations, $\mathrm{G}^{\prime}$ values were higher than $G^{\prime \prime}$ to indicate a solid-like behavior. This behavior is in agreement with the literature regarding the rheology of GF batters (Hüttner, Bello, \& Arendt, 2010; Mariotti et al., 2009; Sciarini, Ribotta, León, \& Pérez, 2012) and gels (Cappa, Barbosa-Cánovas, Lucisano, \& Mariotti, 2016). The addition of chickpea flours to rice dough formulations caused an increase in both $\mathrm{G}^{\prime}$ and $\mathrm{G}^{\prime \prime}$. In particular, CF and DCF showed the highest values for all frequencies investigated and RCF had an intermediate behavior in comparison to RF. A similar increase in $\mathrm{G}^{\prime}$ and $\mathrm{G}^{\prime \prime}$ was previously observed after the addition of chickpea flour (Aguilar et al., 2015) in starch-based gluten-free dough. The damping factor was lower than 1 at all frequencies indicating the prevalence of a solid-like behavior and was slightly affected by the addition of chickpea flour as it remained constant for all formulations; in particular values of $0.41 \pm 0.02,0.41 \pm 0.02,0.42 \pm 0.02,0.37 \pm 0.01$ for RF, $\mathrm{RCF}+\mathrm{RF}, \mathrm{CF}+\mathrm{RCF}$ and $\mathrm{RF}+\mathrm{DCF}$ respectively, were obtained at $1 \mathrm{~Hz}$.

\section{Conclusions}

The nutritional quality of food products is drawing considerable interest due to the increasing awareness of healthy diet. The use of pulse flours in food formulations is becoming an interesting strategy due to the important nutritional benefits of pulses. In this study, the effects of roasted, dehulled and raw chickpea flour when added $(24.85 \mathrm{~g} / 100 \mathrm{~g}$ flour) to rice dough formulations were evaluated. Besides increasing protein and fat content, the addition of all types of chickpea flours created positive effects on the technological performance of the doughs. Although the dough development of the formulations containing chickpea flours was slightly lower than the reference samples, high $\mathrm{CO}_{2}$ retention was evidenced and shorter leavening times were necessary to obtain maximum dough development. Also the viscoelastic properties of the dough were positively affected; higher storage moduli were obtained for the samples containing raw and dehulled chickpea flours. Furthermore, the viscoamylographic test indicated a slower retrogradation tendency of the slurry containing chickpea flours, which is a promising result for baking food applications. This study showed the potential of using raw, dehulled and roasted chickpea flour in combination with rice flour in gluten-free bread formulations.

\section{Declaration of conflict of interest}

The Authors declare that there is no conflict of interest.

\section{Acknowledgements}

This research did not receive any specific grant from funding agencies in the public, commercial, or not-for-profit sectors. The authors would like to thank the Izmir Institute of Technology, Biotechnology and Bioengineering Research and Application Center (BIOMER), and Center for Material Research (CMR) for providing their facilities for raw material analysis and microscopic analysis, respectively. We are grateful to Eigenmann \& Veronelli S.p.A. (Milan, Italy), Prodotti Gianni S.r.L. (Milan, Italy) and As Gida (Istanbul, Turkey) for providing HPMC, DCF flour and instant yeast, respectively.

\section{References}

(Method 08-01.01)(11th ed.). (St. Paul, MN, U.S.A).

Aguilar, N., Albanell, E., Minarro, B., \& Capellas, M. (2015). Chickpea and tiger nut flours as alternatives to emulsifier and shortening in gluten-free bread. Lebensmittel Wissenschaft und -Technologie- Food Science and Technology, 62(1), 225-232.

Alajaji, S. A., \& El-Adawy, T. A. (2006). Nutritional composition of chickpea (Cicer arietinum L.) as affected by microwave cooking and other traditional cooking methods. Journal of Food Composition and Analysis, 19, 806-812.

Alvarez-Jubete, L., Auty, M., Arendt, E. K., \& Gallagher, E. (2010). Baking properties and microstructure of pseudocereal flours in gluten-free bread formulations. European Food Research and Technology, 230, 437-445.

AOAC (1999). Official methods of analysis, protein (total) in flour. (Gaithersburg, MD, USA).

Burešová, I., Kráčmar, S., Dvořáková, P., \& Středa, T. (2014). The relationship between rheological characteristics of gluten-free dough and the quality of biologically leavened bread. Journal of Cereal Science, 60(2), 271-275.

Cappa, C., Barbosa-Cánovas, G. V., Lucisano, M., \& Mariotti, M. (2016). Effect of high pressure processing on the baking aptitude of corn starch and rice flour. LWT-food Science and Technology, 73, 20-27.

Cappa, C., Lucisano, M., \& Mariotti, M. (2013). Influence of Psyllium, sugar beet fibre and water on gluten-free dough properties and bread quality. Carbohydrate Polymers, 98(2), 1657-1666.

Coşkuner, Y., \& Karababa, E. (2004). Leblebi: A roasted chickpea product as a traditional Turkish snack food. Food Reviews International, 20(3), 257-274.

FAO. (2016). FAOSTAT. Available at: http://faostat3.fao.org, Accessed date: 24 May 2016

Ghavidel, R. A., \& Prakash, J. (2007). The impact of germination and dehulling on nutrients, antinutrients, in vitro iron and calcium bioavailability and in vitro starch and protein digestibility of some legume seeds. Lebensmittel-Wissenschaft und -TechnologieFood Science and Technology, 40(7), 1292-1299.

Hüttner, E. K., Bello, F. D., \& Arendt, E. K. (2010). Rheological properties and bread making performance of commercial wholegrain oat flours. Journal of Cereal Science, 52(1), 65-71.

Jukanti, A. K., Gaur, P. M., Gowda, C. L. L., \& Chibbar, R. N. (2012). Nutritional quality and health benefits of chickpea (Cicer arietinum L.): A review. British Journal of Nutrition, 108(S1), S11-S26.

Kahraman, G. (2016). Development of gluten-free bread formulations based on chickpea flour: Optimization of formulation, evaluation of dough properties and bread quality(Doctoral thesis). Izmir, Turkey: Izmir Institute of Technology.

Kaur, M., Singh, N., \& Sodhi, N. S. (2005). Physicochemical, cooking, textural and roasting characteristics of chickpea (Cicer arietinum L.) cultivars. Journal of Food Engineering, 69, 511-517.

Kim, J.-M., \& Shin, M. (2014). Effects of particle size distributions of rice flour on the quality of gluten-free rice cupcakes. Lebensmittel-Wissenschaft und-Technologie- Food Science and Technology, 59(1), 526-532.

Köksel, H., Sivri, D., Scanlon, M. G., \& Bushuk, W. (1998). Comparison of physical properties of raw and roasted chickpeas (leblebi). Food Research International, 31(9), 659-665.

Ma, Z., Boye, J. I., Simpson, B. K., Prasher, S. O., Monpetit, D., \& Malcolmson, L. (2011). Thermal processing effects on the functional properties and microstructure of lentil, chickpea, and pea flours. Food Research International, 44(8), 2534-2544.

Mariotti, M., Cappa, C., Picozzi, C., Tedesco, B., Fongaro, L., \& Lucisano, M. (2017). Compressed yeast and type I gluten-free sourdough in gluten-free breadmaking. Food and Bioprocess Technology, 10(5), 962-972.

Mariotti, M., Lucisano, M., Pagani, M. A., \& Ng, P. K. W. (2009). The role of corn starch, amaranth flour, pea isolate and Psyllium flour on the rheological properties and ultrastructure of gluten-free doughs. Food Research International, 42(8), 963-975.

Ouazib, M., Garzon, R., Zaidi, F., \& Rosell, C. M. (2016). Germinated, toasted and cooked chickpea as ingredients for breadmaking. Journal of Food Science \& Technology, 53(6), 2664-2672.

Reilly, N. R., \& Green, P. H. R. (2012). Epidemiology and clinical presentations of celiac disease. Seminars in Immunopathology, 34(4), 473-478.

Sağlam, H. (2006). Farklı kavurma sıcaklık ve sürelerinin leblebilerin kalitesi üzerine etkisinin incelenmesi(Master's Thesis). Isparta, Turkey: Süleyman Demirel University.

Schober, T. J. (2009). Manufacture of gluten-free specialty breads and confectionery products. In E. Gallagher (Ed.). Gluten-free foods science and technology (pp. 130-180). United Kingdom: Blackwell Publishing Ltd.

Sciarini, L. S., Ribotta, P. D., León, A. E., \& Pérez, G. T. (2012). Incorporation of several additives into gluten free breads: Effect on dough properties and bread quality. Journal of Food Engineering, 111(4), 590-597.

Shevkani, K., Singh, N., Kaur, A., \& Rana, J. C. (2015). Structural and functional characterization of kidney bean and field pea protein isolates: A comparative study. Food Hydrocolloids, 43, 679-689.

USDA. (2016). National nutrient database for standard reference. Available at: http:// www.nal.usda.gov/fnic/foodcomp/search/, Accessed date: 8 August 2017.

Witczak, M., Ziobro, R., Juszczak, L., \& Korus, J. (2015). Starch and starch derivatives in gluten-free systems - a review. Journal of Cereal Science, 67, 46-57. 